\title{
The Falsity of the Reconstruction Conjecture for Tournaments
}

Paul K. Stockmeyer

William \& Mary

Follow this and additional works at: https://scholarworks.wm.edu/aspubs

\section{Recommended Citation}

Stockmeyer, P. K. (1977). The falsity of the reconstruction conjecture for tournaments. Journal of Graph Theory, 1(1), 19-25.

This Article is brought to you for free and open access by the Arts and Sciences at W\&M ScholarWorks. It has been accepted for inclusion in Arts \& Sciences Articles by an authorized administrator of W\&M ScholarWorks. For more information, please contact scholarworks@wm.edu. 


\title{
Erratum to: "The Falsity of the Reconstruction Conjecture for Tournaments"
}

\section{Paul K. Stockmeyer}

\author{
DEPARTMENT OF COMPUTER SCIENCE \\ THE COLLEGE OF WILLIAM AND MARY \\ P.O. BOX 8795 \\ WILLIAMSBURG, VIRGINIA 23187-8795 \\ E-mail: stockmeyer@cs.wm.edu
}

Received September 4, 2008; Revised November 19, 2008

Published online 13 April 2009 in Wiley InterScience (www.interscience.wiley.com).

DOI 10.1002/jgt.20398

It has been brought to my attention by Ramachandran that there is an error in the proof of Theorem 1 in my paper [1]. The theorem is true-the pairs of vertex-deleted tournaments are isomorphic-but the description of the isomorphism is incorrect. The number $r_{i}$ should not be the remainder of $i$ modulo $2^{p_{i}+1}$ as stated, but rather the number in the range $1, \ldots, 2^{p_{i}+1}$ that is congruent to $i$ modulo $2^{p_{i+1}}$. In other words, $r_{i}=\left((i-1) \bmod 2^{p_{i}+1}\right)+1$. With this revised definition, the phrase "(reducing modulo $2^{p}$ if necessary)" becomes superfluous and should be omitted. In Table 1 , the entries $r_{4}$ and $r_{8}$ should both be 4 , not 0 .

Kocay [2] has also pointed out that the original isomorphism description was incorrect, and provided an alternative proof of the theorem. His existence proof avoids the construction of explicit expressions for the isomorphisms.

Finally, there is a typographical error in line 18 on page 22: the equation " $\operatorname{pow}\left(j^{\prime}-\right.$ $i)=p_{j}$ " should read "pow $\left(j^{\prime}-i^{\prime}\right)=p_{j}$ ". 
200 JOURNAL OF GRAPH THEORY

\section{REFERENCES}

[1] P. K. Stockmeyer, The falsity of the reconstruction conjecture for tournaments, J Graph Theory 1 (1977), 19-25.

[2] William L. Kocay, On Stockmeyer's non-reconstructible tournaments, J Graph Theory 9 (1985), 473-476. 